\title{
DESIGN FOR THE PASSENGERS' SUSTAINABLE BEHAVIOUR IN A SCENARIO OF THE IN-FLIGHT CATERING SERVICE
}

\author{
You, Fangzhou; Bhamra, Tracy; Lilley, Debra \\ Loughborough University
}

\begin{abstract}
This research aims to study the passenger's sustainable attitudes, in-flight catering behaviour, and to develop a persuasive model for behaviour change. Current studies towards the in-flight catering waste are primarily focused on dealing the recyclable materials such as cupboard, newspaper and food packaging. In a survey of 624 respondents, the environmental attitude was a poor predictor of environmental behaviour. The survey data were used to develop the persuasive model based on Persuasive Technology. Four phases of the in-flight catering are based on data from the passenger survey. In-flight touchpoints performed with persuasive function is proposed to raise awareness of food waste classification onboard. This study illustrates how persuasive strategies can change the passenger's food-wasting behaviour.
\end{abstract}

Keywords: Sustainability, Human behaviour in design, Ecodesign, User centred design

\section{Contact:}

You, Fangzhou

Loughborough University

Design School

United Kingdom

F.You@lboro.ac.uk

Cite this article: You, F., Bhamra, T., Lilley, D. (2019) 'Design for the Passengers' Sustainable Behaviour in a Scenario of the In-Flight Catering Service', in Proceedings of the 22nd International Conference on Engineering Design (ICED19), Delft, The Netherlands, 5-8 August 2019. DOI:10.1017/dsi.2019.330 


\section{INTRODUCTION}

With the rapid development of the Chinese civil aviation industry, passengers enjoy the safety, comfort and efficiency of high-quality service provided by airlines. However, waste problems are beginning to emerge. At the global level, air passengers produce $0.82 \mathrm{~kg}$ to $2.5 \mathrm{~kg}$ of waste, including catering waste, depending on distance and flight class, with an average of $1.43 \mathrm{~kg}$ (IATA, 2014). Passengers contribute a lot to producing cabin waste since this group constantly consume a large quantity of airline food and accept in-flight service. However, the current research draws much attention on getting rid of household food waste (Diaz-Ruiz, Costa-Font, \& Gil, 2018; Priefer, Jörissen, \& Bräutigam, 2016; Schanes, Dobernig, \& Gözet, 2018; Schmidt, 2016; Visschers, Wickli, $\&$ Siegrist, 2016). The issue of food waste in the airline industry is less addressed.

In-flight catering waste is not only an exasperating problem for the airlines but also for society as a whole as well as the ecosphere. The increasingly fierce competition within the aviation industry has resulted in a gradual increase in the procurement cost of food material. In addition, the oversupply of airline meals brings about food waste that cannot be treated appropriately. According to Li (2003), food waste accounts for $9 \%$ of the total waste of each flight. At the present time, unopened meals are disposed like general waste in the flight. What's worse, airlines resort to a relatively traditional way to deal with in-flight catering waste, i.e. incineration or landfilling, both of which can give rise to different degrees of contamination for the atmosphere and soil.

Traditional catering waste management does not tackle the problem of food waste effectively (Boyd, 2017). Numerous studies have shown that waste recycling is conducive to reducing waste (Hottle, Bilec et al., 2015; Mak, Yu et al., 2018; Pleissner, 2018; Qi \& Roe, 2017; Shearer, Gatersleben et al., 2017). Recycling is beneficial to the restoration of natural environment and recyclable materials can create economic value. For instance, LIFE Zero Cabin Waste is a project aiming at reducing in-flight catering waste. This project mainly focuses on recoverable materials and solid waste from both international flights and EU flights (Life \& Policy, 2015). Additionally, this project is designed to train airline personnel to collect cabin waste by its category onboard so as to provide convenience for the on-ground waste recycling.

\subsection{Airline catering process}

In order to understand the process of airline catering, the first author conducted an interview with the cabin manager of China Eastern Airlines. A follow-up field study about catering equipment took place after the interview. The following steps, derived from the data collected, demonstrate the general process of airline catering.

The airline cabin service department designs the meal plan based on the cabin class, voyage and the time period. The standards for airplane meals are generally as follows: short-haul flight provides passengers with a cold meal containing a piece of bread, sandwich and snacks; medium-haul flight supplies passengers with a hot meal and a cold meal; two or three meals are offered on a long-haul flight.

The meal plan is normally made on the basis of the number of seasonal flights and the attendance rate of each flight as well as the number of sold seats. Then the menu is developed, and food ingredients are purchased. According to the field study conducted in China Eastern Airlines, the production process of airline food is as follows:

Firstly, the aviation catering department prepares the fresh ingredients at the day, while the ready-toeat food including packaged food is prepared in advance. Three types of food are provided in every meal box including a salad and a main course served with rice or noodles. Before meals are delivered to the plane, they must be placed in the fridge at $-18{ }^{\circ} \mathrm{C}$ to keep them fresh. The actual loaded meals are allocated in accordance with the actual number of passengers on the plane. The aviation catering vehicle transports airline food to the aeroplanes before take-off. Secondly, an onboard convection oven is used for re-heating meals. The prepared meals and drinks are put in catering trolleys. Thirdly, flight attendants distribute meals and beverages to passengers by passing through the aisles. And then, food waste is collected by flight attendants after passengers finish their meals. In the end, a cleaning team is responsible for collecting waste when the flight lands. Cleaning staff need to sort all the cabin waste and send it to the designated waste plants. Catering waste is sent to municipal waste treatment 
plants along with other types of the cabin waste. With regard to the handling methods of the cabin waste, incineration and landfill are preferred.

The airline catering process, including the airline meal production, is illustrated in Figure 1.

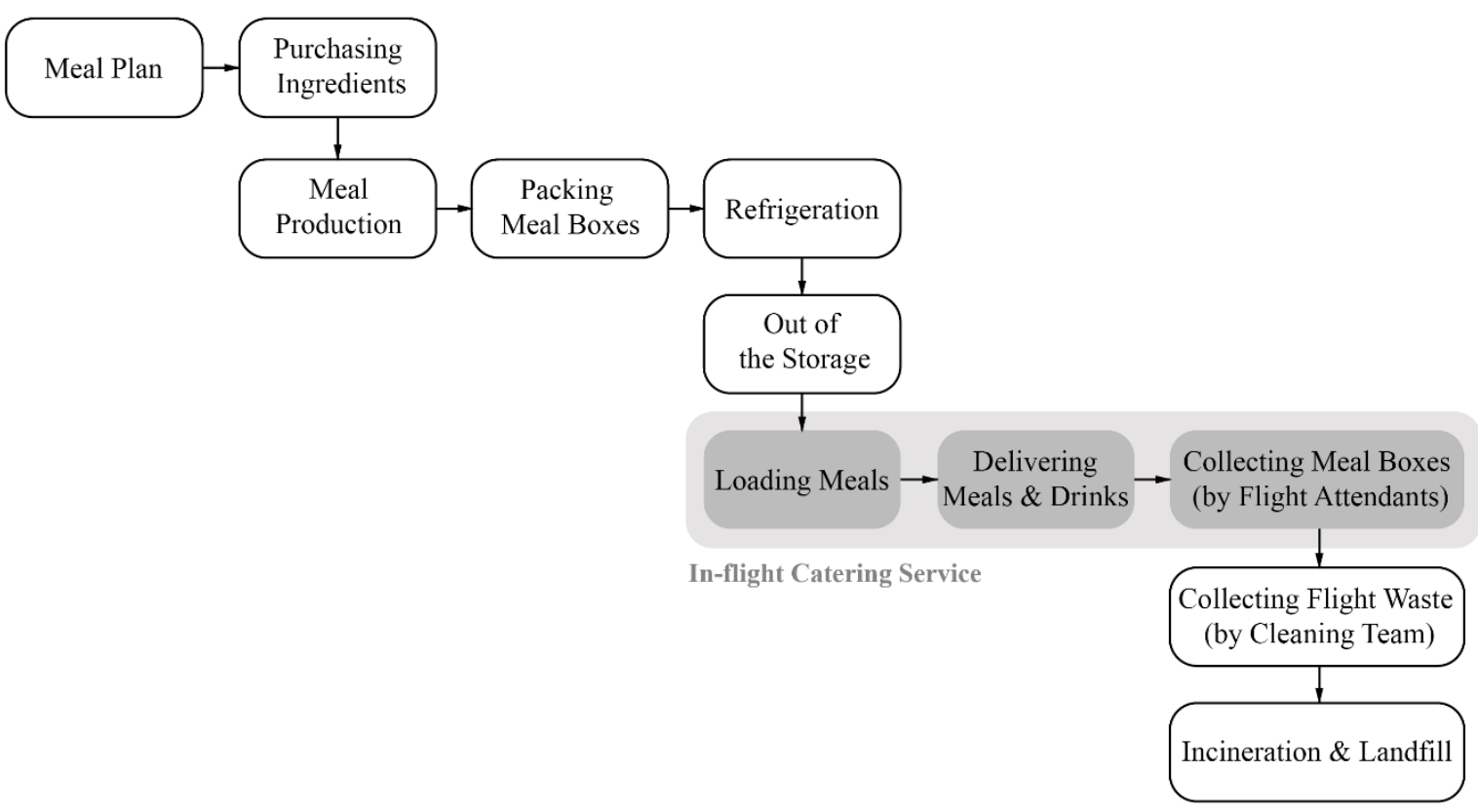

Figure 1. China Eastern Airlines Catering Process (Source: First Author)

\subsection{User-centred design for food-wasting behaviour}

Under this circumstance, food waste includes food packaging, unconsumed food, and unopened food. The remaining food is considered as waste whether the meals have been opened or not. Therefore, this research focuses on the in-flight food service and proposes design opportunities by understanding the passengers' behaviour.

Food waste should be dealt with according to the characteristics of each category to ensure that it can be recycled effectively. The in-flight catering service consists of three phases, namely serving, eating and the collection of meal boxes. The majority of food waste is generated by passengers in the last two phases due to their eating behaviour.

There are many reasons for waste generation since negative impacts of food waste is determined by consumers' behaviours (Tuomivaara, 1990). Personal behaviour, as one of the preceding interpretations, indicates that individuals are both a source of environmental issues and a potential solver (United Nations, 2016). Nevertheless, insights into consumer food waste behaviour can make contributions to food waste prevention (Lyndhurst, Cox and Downing, 2007) through promoting personal behaviour change. Persuasive Technology (Fogg, 2003) is one of the potential strategies for influencing users' behaviour in the product design (Lilley, 2009). What's more, consumers are supposed to possess the greatest potential to reduce food waste (Parfitt, Barthel and MacNaughton, 2010). In other words, air passengers, as the consumers in the aviation industry, could play a significant role in in-flight catering waste reduction. Hence, passengers are the objective in this research because they are consumers of the in-flight catering. Additionally, passengers' behaviour of airline food waste is the targeted behaviour to be investigated.

The significance of User-centred Design (UCD) has been highlighted by several perspectives that emphasise the importance of user participation in the development process (Flach and Dominguez, 1995; Norman, 2002; Wever, van Kuijk and Boks, 2008). User-centred Design has also been widely adopted in the development of sustainability since the research points out that besides technological aspects, the environmental impact of the product in the process of using can be reduced if considered from the perspective of users' behaviour (Rodriguez and Boks, 2005; Tang and Bhamra, 2008; Lilley, 2009). Moreover, User-centred Design is able to work out solutions that encourage sustainable behaviour, thereby reducing environmental impacts during use. Therefore, passengers' self-reports and a questionnaire are used to collect data in order to identify opportunities to reduce food waste. 


\section{METHODOLOGY}

This research follows a Design Research Methodology (DRM) (Blessing, Chakrabarti and Blessing, 2009) which concentrates first on the current airline catering system and points out the main problems. Then, passengers' behaviours are analysed to identify potential design strategies by conducting a questionnaire survey and passenger journey map respectively. Please see Figure 2.

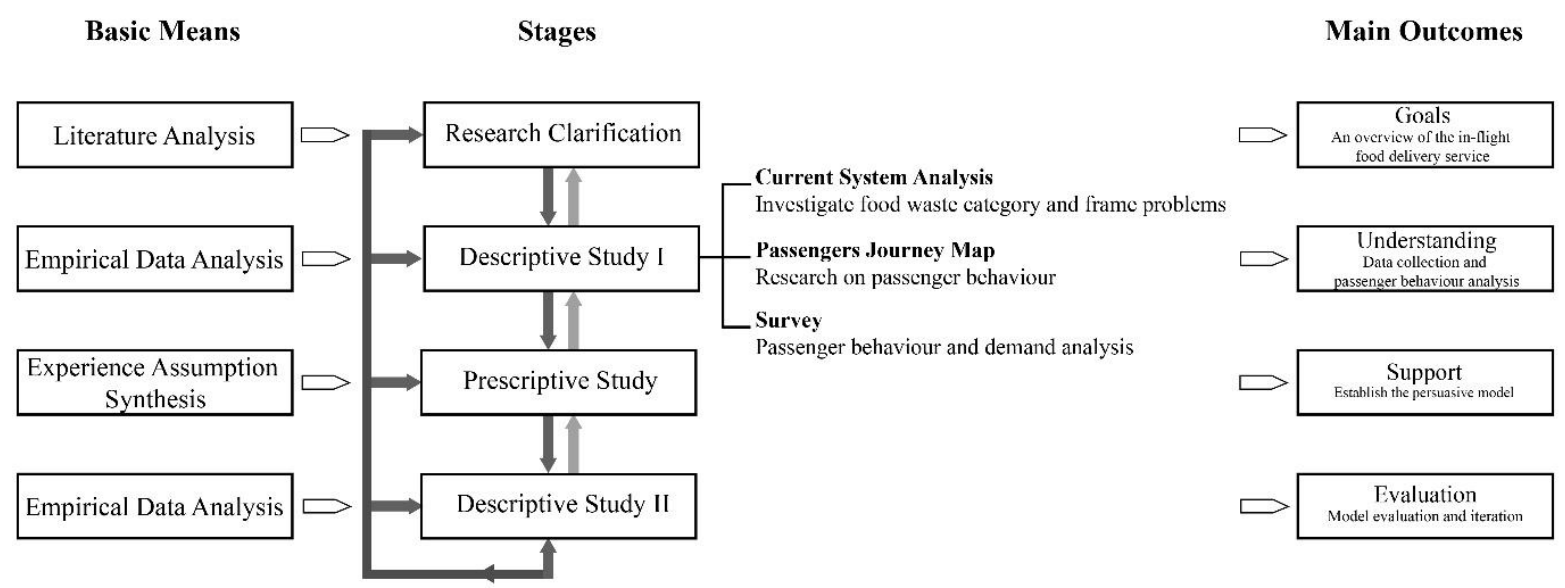

Figure 2. Design Research Methodology (Source: Adapted from Blessing \& Chakrabarti, 2009)

\section{METHODS}

A survey was applied in this study to acquire passengers' attitudes towards in-flight catering waste. The influencing factors related to food waste behaviour were also collected. The obtained data were visualised through a passenger's journey map, which defines design opportunities and contributes to a persuasive model for inducing behaviour change

\subsection{Survey}

This research selected frequent fliers as the respondents of this study. A questionnaire was designed to have a better understanding about their onboard behaviour patterns. In total, 624 valid questionnaires were collected, including those of $30.13 \%$ male respondents and $69.87 \%$ female respondents.

The questionnaire was made up of the following sections, which were combined and programmed into an online survey using WJX:

- First, it included questions to help the researcher understand the environmental knowledge of passengers.

- Second, tests about passengers' new media literacy were included, which aimed at understanding whether passengers can accept new media; whether they are influenced with the spread of new media; and to what extent new media plays a positive role in behavioural persuasion.

- Third, there were questions to understanding the passengers' current situation of classifying food waste onboard. The questions were designed not only to investigate passengers' attitudes, perceived effectiveness, intention, subjective norms, perceived behaviour control and their behaviour concerning classifying food waste onboard, but also to forecast the possibility of passengers' engaging in food waste classification in the future;

- Fourth, it included the behavioural and emotional demands of passengers in accelerating food waste classification onboard.

\subsubsection{Reliability and validity}

A testing of reliability and a testing of validity provided the validity and rigour of this survey. In order to explore the specific characteristics of the passengers' psychological and behavioural status concerning food waste classification, this research adopted an independent sample t-test and one-way ANOVA to analyse the psychology of the passengers' regard to the food waste classification and test 
the differences in behavioural status between demographic variables. This study conducted a reliability and validity test of the questionnaire to ensure the reliability and stability of the questionnaire and data. The reliability of the 624 questionnaires is tested by SPSS21.0 software. The general definition of the alpha reliability (Cronbach's alpha) indicates that if alpha values of 0.7 to 0.8 are rated as satisfactory (Bland and Altman, 1997), which means the questionnaire is reliable. However, the questionnaire is relatively weak if alpha values are lower than 0.7 , then the result is unreliable. Therefore, each dimension of the questionnaire is desirable-designed. The reliability of each section in the questionnaire is shown in Table 3.

Table 3. Questionnaire reliability coefficient

\begin{tabular}{|l|c|r|}
\hline Questionnaire Dimensions & $\begin{array}{c}\text { Number of } \\
\text { Questions }\end{array}$ & $\begin{array}{r}\text { Reliability } \\
\text { Coefficient }\end{array}$ \\
\hline Passenger's Environmental Knowledge & 3 & 0.727 \\
\hline Passenger's Emotional Demand & 3 & 0.844 \\
\hline Passenger's Perceived Effect & 3 & 0.793 \\
\hline Passenger's Attitudes & 3 & 0.765 \\
\hline Passenger's Subjective Norms & 3 & 0.745 \\
\hline Passenger's Perceived Behaviour Control & 3 & 0.853 \\
\hline Passenger's Behavioural Demands & 3 & 0.796 \\
\hline Passenger's New Media Literacy & 5 & 0.728 \\
\hline Passengers' Operational Requirements of Food Waste & 13 & 0.897 \\
Classification & & \\
\hline Overall & 39 & 0.934 \\
\hline
\end{tabular}

The structural validity is the most potent indicator for evaluating the validity of the scale. In this study, confirmatory factor analysis is performed by Amos21.0, and the fitting parameters of the structural equation model are obtained as indicators for measuring structural validity. The results are shown in Table 4. The CMIM / DF is the primary index of overall model adaptation; the standard of model adaptation is that CMIM/ DF is less than 3. NFI is the normative adaptation index of the model. If the NFI is close to 1 , it indicates that the theoretical model changes the virtual model. Supposing the NFI is close to 0 , then it suggests that the difference between the conceptual model and the virtual model is not significant. That NFI is higher than 0.90 is the standard for model adaptation. GFI is a useful adaptation index of the model, indicating that the theoretical model can explain the variation and covariation of the observed variables. The standard for model adaptation is that GFI is over 0.90. CFI is the model comparison adaptation index, which is between 0 and 1 . Besides, the standard for model adaptation is that CFI is higher than 0.90. The RMSEA is an index that approximates the fit by approximating the error rms. When the RMSEA value is lower than 0.05 , the model fits well. Based upon the above criteria, the appropriate model indicators used in the questionnaire all meet the adaptation criteria. Therefore, it can be concluded that the questionnaire has good structural validity, and the questionnaire items and dimensions are well set. Please refer to Table 4.

Table 4. Structural validity of the questionnaire

\begin{tabular}{|l|c|c|c|r|}
\hline CMIN/DF & NFI & GFI & CFI & RMSEA \\
\hline 2.024 & 0.908 & 0.901 & 0.951 & 0.041 \\
\hline
\end{tabular}

\subsubsection{Results}

The passengers generally do not have a comprehensive understanding of airline catering and environmental knowledge related to airline catering when they are given in-flight service, because the relevant knowledge is not widely publicised to passengers. In terms of environmentally friendly behaviour, $93.3 \%$ of the passengers indicate that they are willing to participate in the classification of food waste onboard, and their attitudes towards environmentally friendly behaviour is relatively positive. With regard to gender variables, women pay more attention to the safety of onboard behaviour than men who emphasise the item entitled "no need to get up and walk to complete the food waste". 
In the comparison of age variables, respondents aged 40-49 pay more attention to the screen and video information. They think that people should make full use of onboard broadcasting, different colour recycling bags and instruction manuals to guide the classification of food waste. Respondents aged 2939 are more likely to receive recognition for accomplishing sustainable behaviour. In the comparison of the educational level variables, in addition to the respondents with masters degree, or doctorates, the respondents of other educational levels emphasise the guiding role of the touch screen, onboard broadcasting and the flight manual on sustainable behaviour. Furthermore, respondents with graduate degrees and above are more likely to receive awards for their sustainable behaviour. In terms of occupation variables, students are more likely to receive recognition for accomplishing sustainable behaviour than respondents of other professions.

The passenger journey map visualises passengers' in-flight activities and the touchpoints that passengers interact with, which offers an insight into emotional and physical experience. This map provides design opportunities when implying behaviour change strategy.

Touchpoints are divided into two categories within the in-flight context: 1) physical touchpoints, including onboard broadcasting, TV, small table, the safety manual and the service bell; 2) interpersonal touchpoints, i.e. flight attendants and peer passengers. Passengers' in-flight behaviours are showed in Figure 3.

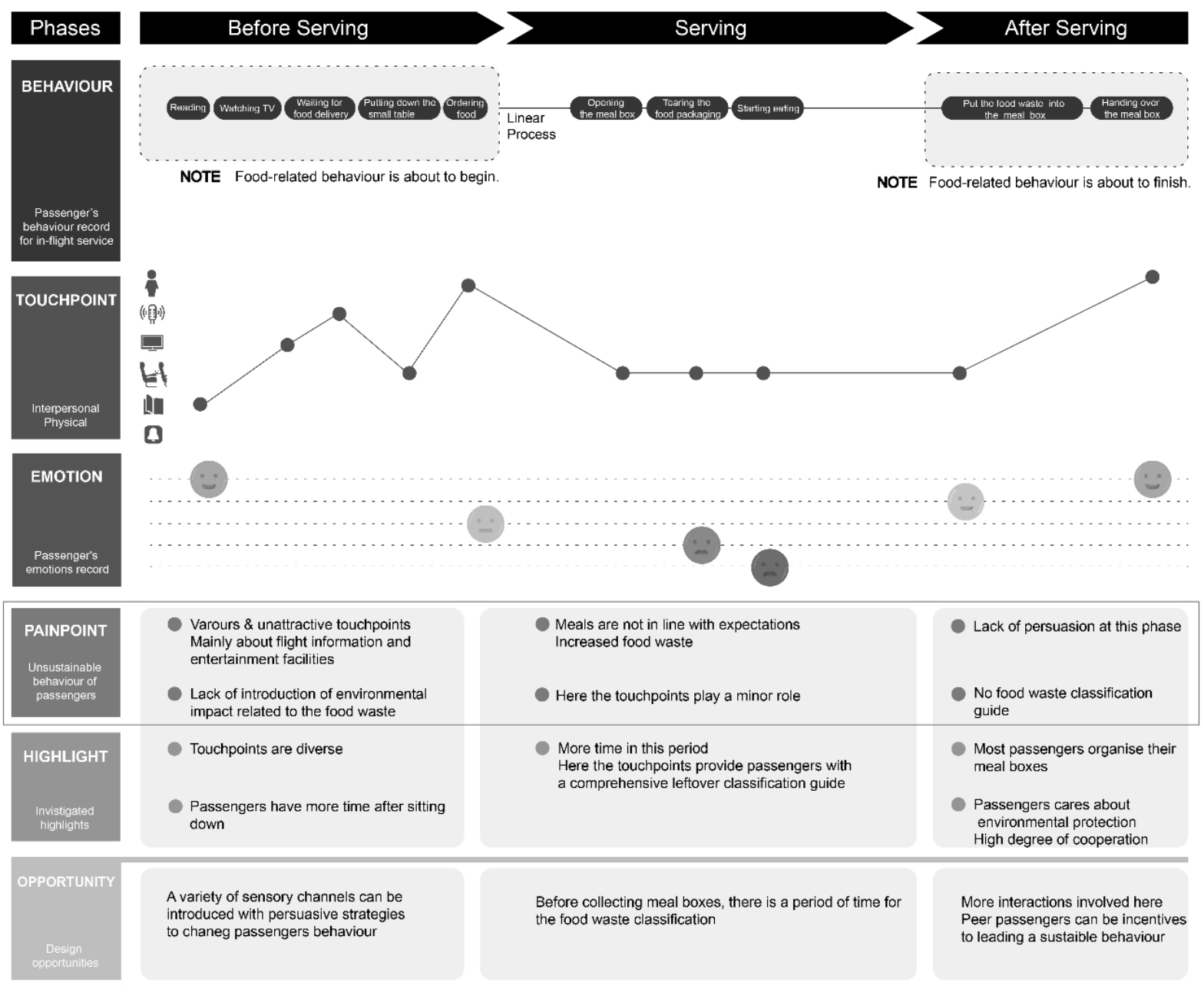

Figure 3. Passenger journey map (Source: The Author)

\section{BEHAVIOUR INTERVENTION}

Design for Sustainable Behaviour (DfSB) as a design strategy aims at designing products and service that will achieve comparatively sustainable use. The behaviour intervention provides the possibility of stopping food-wasting behaviour through a behaviour change strategy. 
Behaviour change approaches aiming at changing food-wasting behaviour may be effective in behaviour intervention design. Persuasive technology plays a crucial role in the behaviour intervention since it is integrated as the trigger for a target behaviour (Fogg, 2003). The behaviour intervention can result in smart products or systems to guide individual behavioural changes. For example, ecofeedback allows users to understand the environmental impact of the products and services they purchase, which will convince users to change or adjust their behaviours (Wever, van Kuijk and Boks, 2008; Lilley, 2009).

\subsection{Triggers of sustainable behaviour}

Fogg's Behaviour Model (2008) puts forward the three most important factors for shaping a target behaviour: motivation (spark), ability (facilitator) and behaviour trigger (signal) respectively. A target behaviour, in this research, is the food waste classification conducted by passengers. It can not only raise passengers' awareness of reducing food waste but also persuade them to take sustainable actions. Onboard waste classification can be very helpful to on-ground waste sorting and improves the opportunity of the waste recycling. This model examines three factors that promote sustainable inflight behaviour. Onboard touchpoints have the potential to be pivotal triggers for passengers' food waste classification. A model is established for discouraging the in-flight behaviour, which can be seen in Figure 4. It indicates that persuasive design strategies are implemented into interpersonal touchpoints and physical touchpoints of the cabin. The three factors in the circles below constitute a target behaviour.

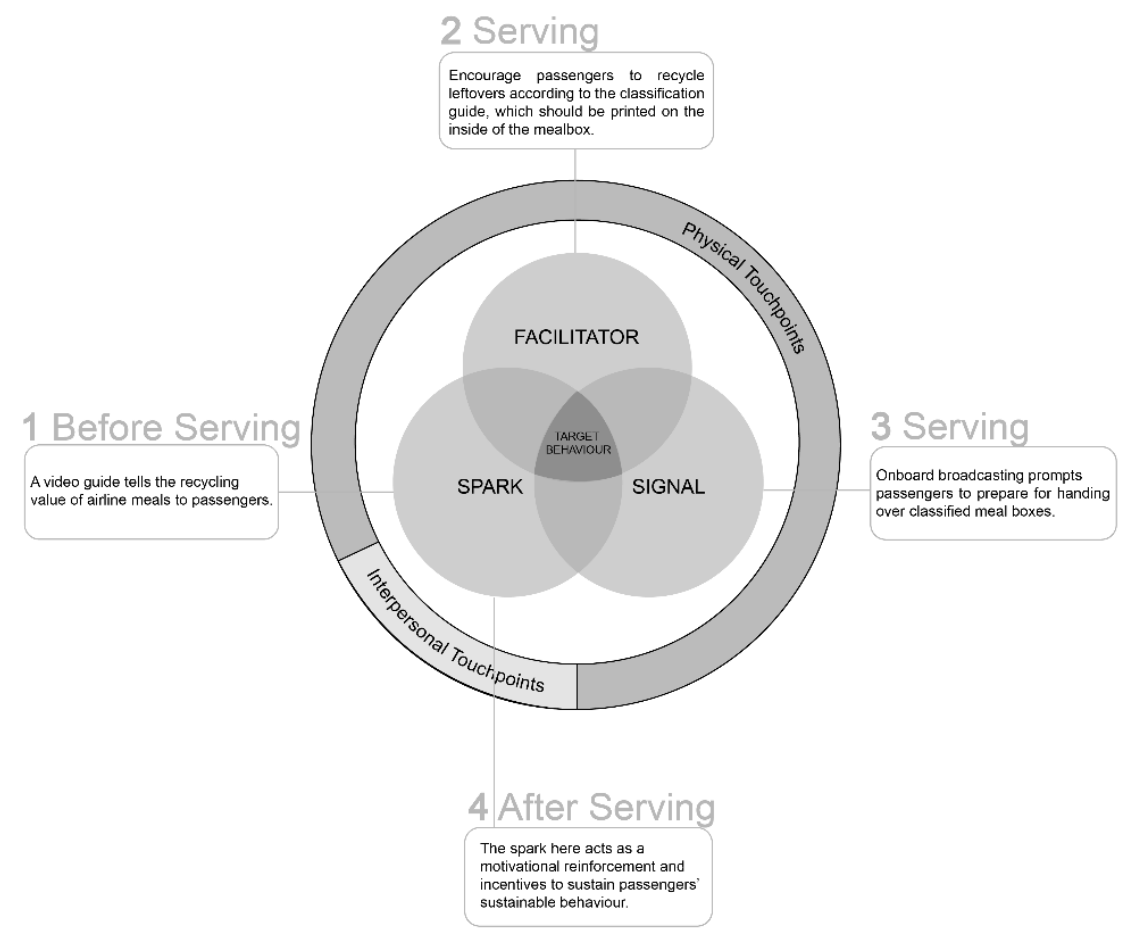

Figure 4. Persuasive model based on the in-flight interactive touchpoints (Source: The Author)

Firstly, it is the spark that occurs before eating meals. The touchpoint mainly reminds the passengers of airline meal's value represented in the form of a video guide. The passengers then receive this information and their attention is attracted. After they understand the relevant knowledge, their motivation at this time is higher than before. Secondly, a guide to the food waste classification on the inner lid of the meal box is an effective instruction on guiding passengers to classify the food waste since it may attract passengers' attention while eating. Colour-coded information may catch passengers' eyes quickly and is beneficial to classifying different catering waste. This information as guidance strengthens the sustainable awareness of passengers. Additionally, onboard broadcasting can remind passengers that flight attendants will collect the meal boxes later. In order to maintain the good behaviour of food waste classification, passengers should be rewarded when they achieve sustainable behaviour in that rewards can supply passengers with motivational incentives and make them keep 
long-term habits. Based on acquired survey data and the theory of persuasive technology, the preceding three factors were embedded into each in-flight catering phase to persuade passengers into choosing the sustainable behaviour.

\subsection{Persuasive design strategy}

The strategies for behavioural change comply with the abovementioned persuasive model. By following these strategies, the behavioural change is likely to be achieved by passengers.

(1) Strategy 1: a video guide of food waste classification

According to the survey, the lack of publicity about avoiding food waste in the flight is a great factor in unsustainable behaviour. A signal should be sent to passengers in order to change their original behaviour pattern. Therefore, after the passengers are seated, the video guide should be made full use of to spread knowledge about the classification of food waste, which should be transmitted after playing the safety video but before the food delivery. It can catch passengers' attention and instruct passengers from the cognitive level. The example is shown in Figure 5.

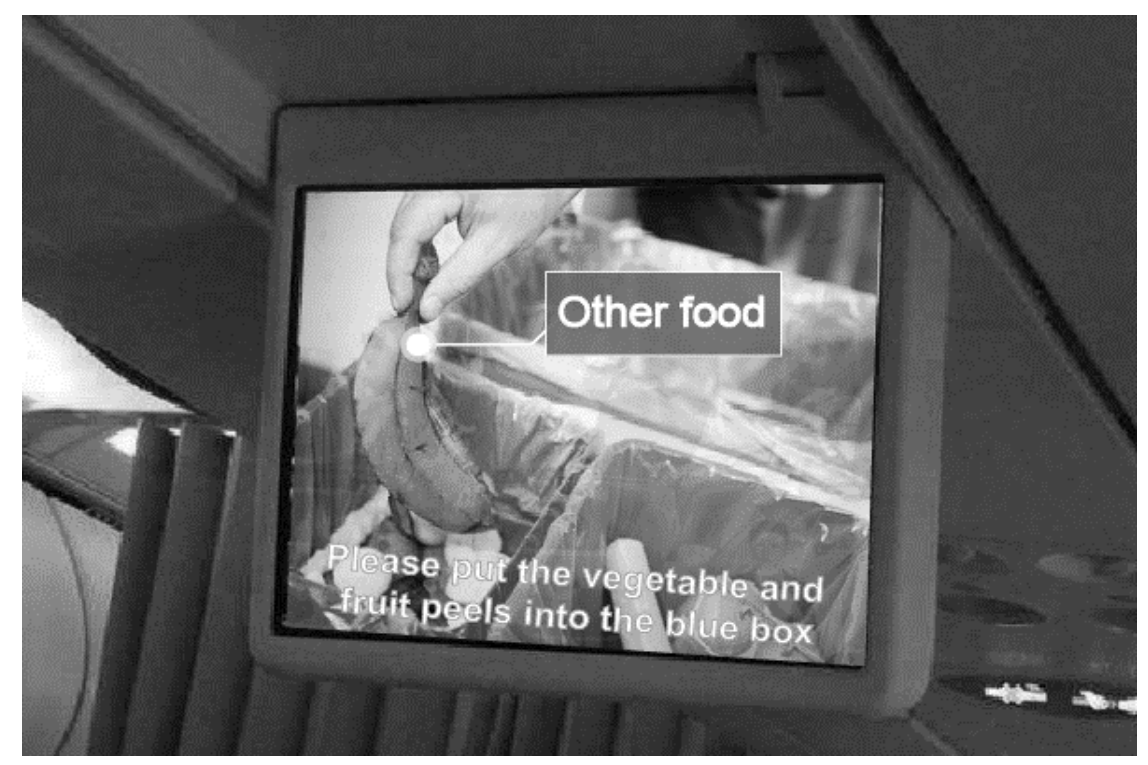

Figure 5. Food waste classification video (Source: Adapted by The Author)

(2) Strategy 2: A Printed Guide for Food Waste Classification

Persuasive design can be integrated with the meal boxes by adding colour-coded indicators. The guide of food waste classification should be designed to be as simple and clear as possible. The colour-coded information classifies unconsumed food by its category, such as unconsumed packaging food, cereals and other types of food. An example is illustrated in Figure 6.

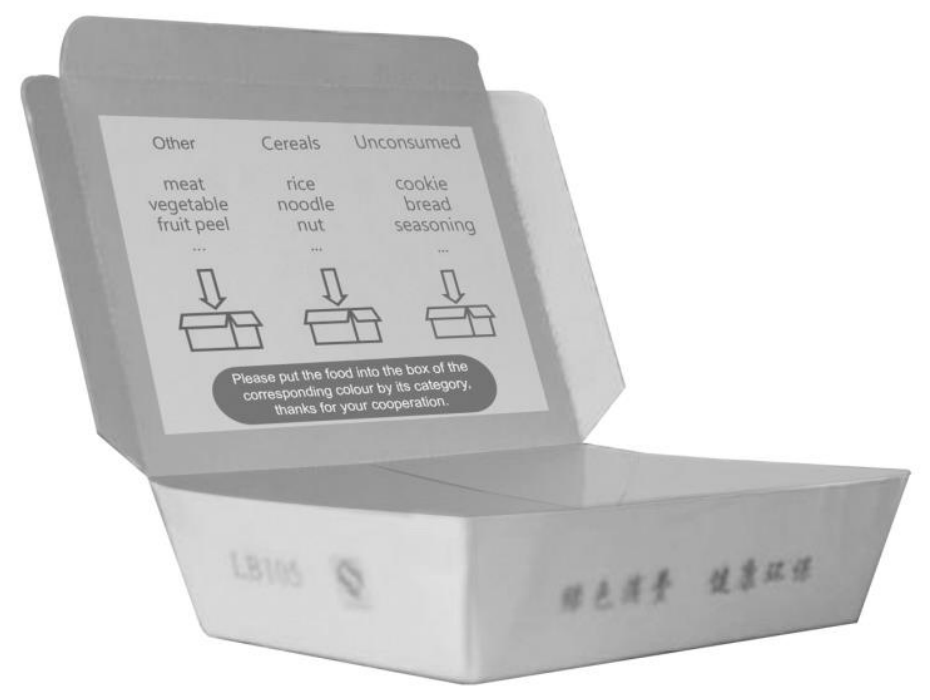

Figure 6. Food waste classification guidance (Source: The Author) 
(3) Strategy 3: Onboard Broadcasting

The onboard broadcasting can give passengers a signal that reminds passengers to keep the food waste classification in their mind and to prepare for waste collection. This scenario is illustrated in Figure 7.

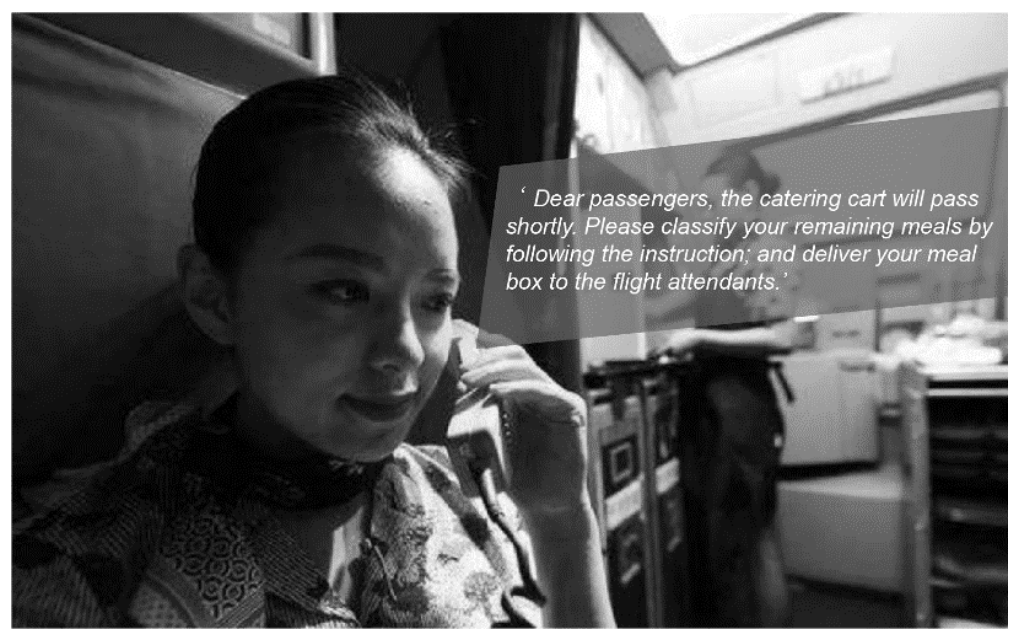

Figure 7. Onboard broadcasting (Source: Adapted by The Author)

(4) Strategy 4: Intervention of Flight Attendants and Other Passengers

Flight attendants and the peer passengers are parts of interpersonal touchpoints. Peer passengers with more experience in recycling will provide skills and support for passengers who are trying to classify the food waste on the flight for the first time. The assistance and encouragement of flight attendants will also affect the attitudes and behaviours of passengers; thus, flight attendants also act as a behavioural reinforcement. Consequently, the persuasive design should be considered from the people touchpoints. For example, flight attendants should reward passengers if they take actions to classify the food waste.

\section{CONCLUSION}

The persuasive model produced in this research is applicable to some extent. For example, designers can establish standards to enhance the persuasive effectiveness when implementing design in the future. For the designer, the design principles of the onboard interactive touchpoints and persuasive model can provide guidance and be utilized for defining the application scenarios for the persuasive design, and ultimately determine the design goals. For passengers, the classification of food waste onboard is an emerging environmental behaviour. The behavioural changes of passengers can reduce the waste of aviation meals. For airlines, this disposal of food waste can be used as an example in the industry, which not only reflects the company's awareness of responsibility for environmental protection but also reduces the economic pressure caused by the high cost of meal production. In addition, the guidance of food waste classification and the recycling scheme proposed in this research can provide new ideas for airlines in food waste recycling.

\section{REFERENCES}

Bland, J. M. and Altman, D. G. (1997), "Statistics notes: Cronbach's alpha”, BMJ, Vol. 314, p. 572.

Blessing, L. T. M., Chakrabarti, A. and Blessing, L. T. M. (2009), "DRM, A Design Research Methodology”, p. 397. https://doi.org/10.1007/978-1-84882-587-1.

Boyd, O. (2017), The ridiculous story of airline food and why so much ends up in landfill | Guardian Sustainable Business | The Guardian. Available at: https://www.theguardian.com/sustainable-

business/2017/apr/01/airline-food-waste-landfill-incineration-airports-recycling-iberia-qantas-united-virgin (Accessed: 17 December 2018).

Flach, J. M. and Dominguez, C. O. (1995), "USE - Centered Design: Integrating the User, Instrument, and Goal", Ergonomics in Design: The Quarterly of Human Factors Applications. https://doi.org/10.1177/106480469500300306.

Fogg, B. J. (2003), Persuasive Technology: Using Computers to Change What We Think and Do, Persuasive Technology: Using Computers to Change What We Think and Do. https://doi.org/10.1016/B978-1-55860643-2.X5000-8. 
Fogg, B. J. (2008), BJ Fogg's Behaviour Model, Behaviour Model. org. https://doi.org/10.1016/j.wasman.2011.11.018.

$\mathrm{Li}$, X. D. et al. (2003), "Waste reduction and recycling strategies for the in-flight services in the airline industry", Resources, Conservation and Recycling. Elsevier, Vol. 37 No. 2, pp. 87-99. https://doi.org/10.1016/S0921-3449(02)00074-5.

Lilley, D. (2009), "Design for sustainable behaviour: strategies and perceptions", Design Studies. Elsevier, Vol. 30 No. 6, pp. 704-720. https://doi.org/10.1016/J.DESTUD.2009.05.001.

Lyndhurst, B., Cox, J. and Downing, P. (2007), "Retail Programme -Food Waste: Final Report", Waste \& Resources Action Programme (WRAP), (December 2006).

Norman, D. A. (2002), “The Design of Everyday Things”, The Electronic Journal of Communication. https://doi.org/10.1002/hfm.20127.

Parfitt, J., Barthel, M. and MacNaughton, S. (2010), "Food waste within food supply chains: Quantification and potential for change to 2050", Philosophical Transactions of the Royal Society B: Biological Sciences, Vol. 365 No. 1554, pp. 3065-3081. https://doi.org/10.1098/rstb.2010.0126.

Rodriguez, E. and Boks, C. (2005), "How design of products affects user behaviour and vice versa: The environmental implications", in Proceedings - Fourth International Symposium on Environmentally Conscious Design and Inverse Manufacturing, Eco Design 2005. https://doi.org/10.1109/ECODIM.2005.1619166.

Tang, T. and Bhamra, T. (2008), "Understanding Consumer Behaviour to Reduce Environmental Impacts through Sustainable Product Design”, in DRS2008.

Tuomivaara, L. M. (1990), "Ectopic Pregnancy and Genital Infections: A Case-Control Study", Annals of Medicine, Vol. 22 No. 1, pp. 21-24. https://doi.org/10.3109/07853899009147235.

United Nations. (2016), “Education for people and planet : Creating Sustainable Futures for All”, Unesco. https://unesdoc.unesco.org/ark:/48223/pf0000245752

Wever, R., van Kuijk, J. and Boks, C. (2008), "User-centred design for sustainable behaviour", International Journal of Sustainable Engineering, Vol. 1 No. 1, pp. 9-20. https://doi.org/10.1080/19397030802166205.

\section{ACKNOWLEDGMENTS}

Thanks to the China Scholarship Council for supporting this research. 